\title{
Aseismic study of a building with the efficiency-enhanced damping system
}

\author{
S. S. Ke ${ }^{1}$, W. S. $\mathrm{Li}^{1}$ \& B. J. Shih ${ }^{2}$ \\ ${ }^{I}$ National Science and Technology Center for Disaster Reduction, Taiwan \\ ${ }^{2}$ Department of Civil Engineering, \\ National Taipei University of Technology, Taiwan
}

\begin{abstract}
The objective of the present paper is to demonstrate the effectiveness of the efficiency-enhanced damping system (EDS) on the reduction of seismic vibrations of building structures with the device. Due to the limited damper stroke, the application of linear fluid dampers on buildings is restrained and dampers are usually installed as the diagonally auxiliary member. The EDS consists of linear fluid dampers and relatively rigid linking members to formulate a leverage mechanism for improving the capacity of damper efficiency by increasing the input velocity of the damper according to the arm ratio between the connecting lengths of the structural member and dampers. Through the adjustment of arm ratio, the input velocity of the damper will be magnified.

Two principal topics are focused on in this paper: first, to theoretically and numerically identify the feasibility and effectiveness of the EDS on the improvement of aseismic capability of buildings; second, to verify the accuracy of results and the related limitations between the theoretical analysis and numerical simulation through shaking table experiments. From the experimental observation and simulation results, the damping ratio of building structures will be largely increased and the seismic responses of the model building will be obviously reduced by adopting the EDS. As a consequence, the heavily damped structure systems do show a lot of potential for this application in civil engineering.

Keywords: efficiency-enhanced damping system, structure control, fluid damper, shaking table experiment, response spectrum analysis.
\end{abstract}




\section{Introduction}

It has been pointed out that the linear fluid damper is one of the promising energy dissipaters both in buildings and bridges for the following reasons [1]: (1) the low cost, (2) no external power supply is required, (3) the wide range of the operation temperature, (4) it is reliable and (5) it is almost maintenance free. In addition, due to the low axial stiffness when a damper is operated below its cut-off frequency and the damping coefficient remains constant, the dynamic analysis of a structure with linear fluid dampers remains linear. This makes it suitable for use in strengthening structures against ground motions.

According to the seismic design code in Taiwan, the relative story drift ratio should not exceed the 5/1000 of story height. For example, the maximum story drift will be $1.65 \mathrm{~cm}$ with $3.3 \mathrm{~m}$ story height. If the behaviors of beam and column are confined in elastic range under earthquake, the allowable drift should be very limited. The efficiency and effectiveness of linear fluid damper will not be demonstrated, due to small stroke. To apparently increase the energy dissipation of damper, the EDS is proposed to meet the designed demand and provide a robust mechanism to expand further feasibility of the device.

The EDS consists of linear fluid dampers and relatively rigid linking members to formulate a leverage mechanism (shown in Figure 1) for improving the capacity of damper efficiency by increasing the input velocity of damper according to the arm ratio between the connecting lengths of structural member and dampers. Through the adjustment of arm ratio, the input velocity of damper will be magnified. The magnifying effect of EDS is simply shown in Figure 2 [2].

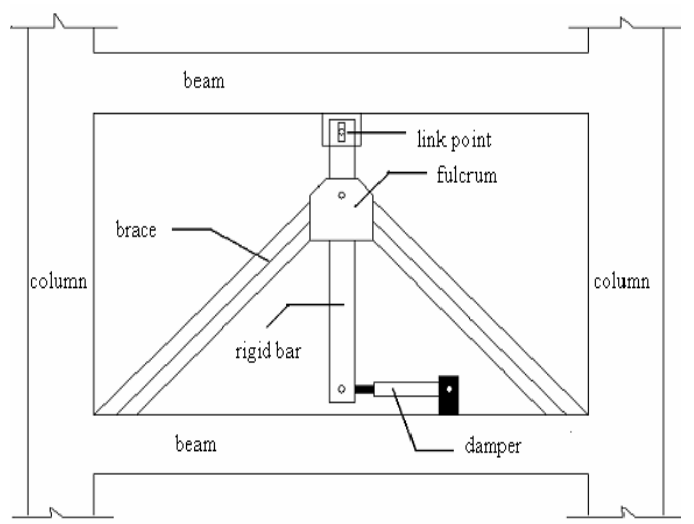

(a)

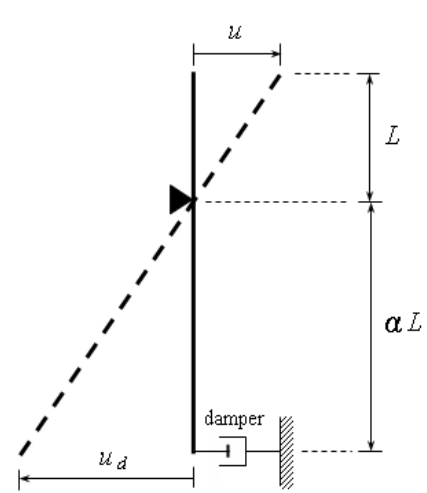

(b)

Figure 1: (a) Building with added damper and linking members. (b) Function mechanism of EDS. 


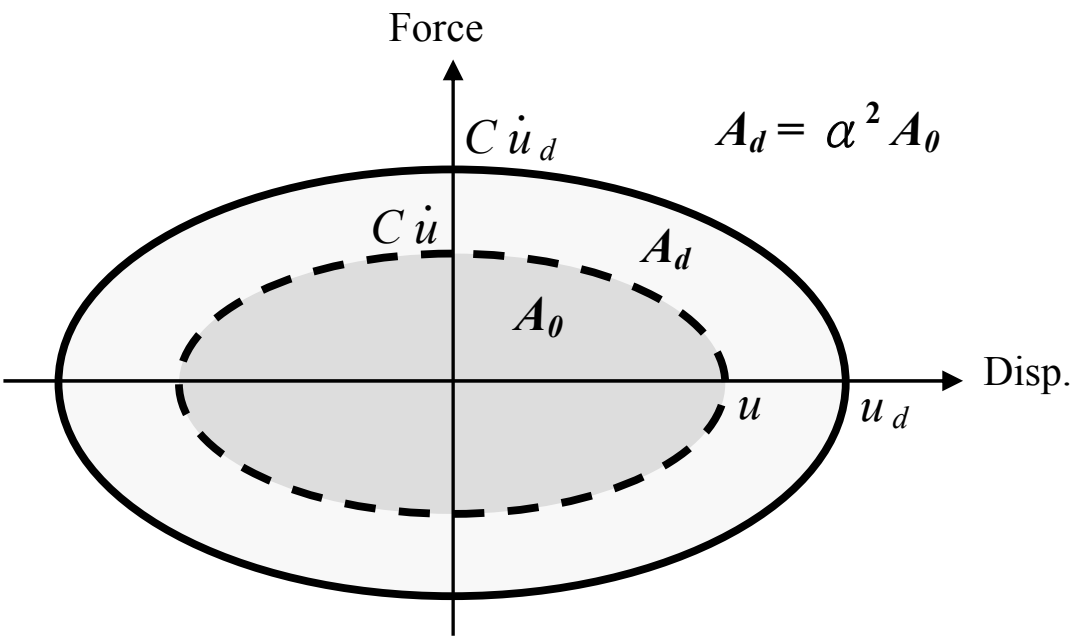

Figure 2: The conceptual illustration of EDS's efficiency.

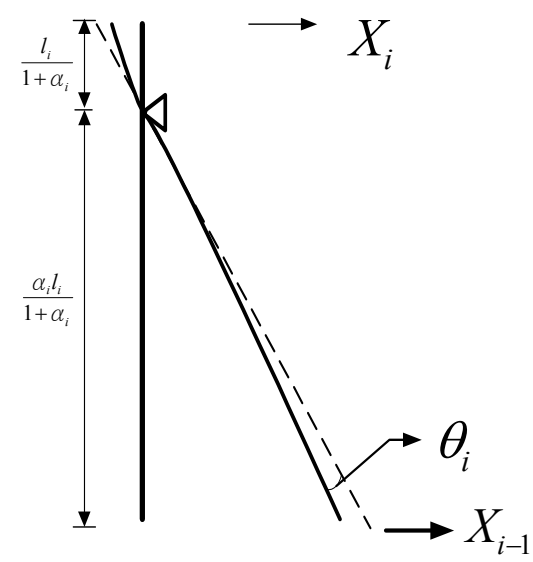

(a)

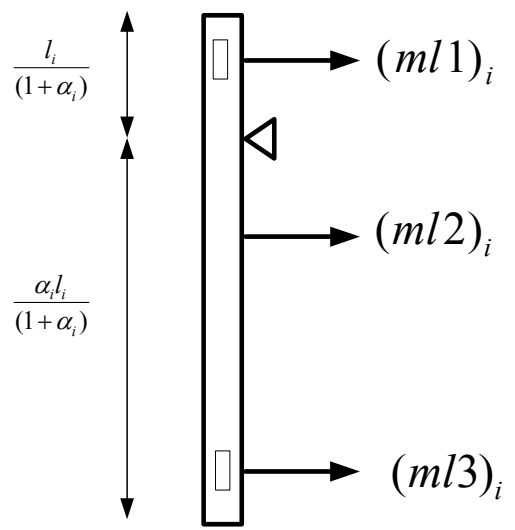

(b)

Figure 3: (a) Coordinates system of leverage mechanism. (b) Mass distribution of leverage.

\section{Theoretical formulation}

The derivation of EDS's equations of motion to formulate the relative deformations between upper and lower decks is depicted as the coordination system shown in figure 3 [3]. 
In equation (1) representing the kinematic energy of system, the components are composed of constitution from deck movement plus translational and rotational motion of leverage. For a simplified model, only the movements relative to leverage pivot are taken into account.

$$
\begin{gathered}
T=\sum_{i=1}^{N}\left(\frac{1}{2} M_{i} \dot{X}_{i}^{2}+\frac{1}{2}(m l 2)_{i} \dot{X}_{i-1}^{2}\right) \\
+\sum_{i=1}^{N} \frac{1}{2}(m l 3)_{i}\left[\alpha_{i}\left(\dot{X}_{i}-\dot{X}_{i-1}\right)-\frac{2 \alpha_{i} \dot{\theta}_{i} l_{i}}{\left(1+\alpha_{i}\right)}-\dot{X}_{i-1}\right]^{2} \\
+\sum_{i=1}^{N} \frac{1}{2}\left(I_{\alpha}\right)_{i}\left[\frac{\left(1+\alpha_{i}\right)}{l_{i}}\left(\dot{X}_{i}-\dot{X}_{i-1}\right)-\dot{\theta}_{i}\right]^{2}
\end{gathered}
$$

$\theta_{i}:$ the leverage rotation in $i$ th floor

$\mathrm{N}$ : number of story

$l_{i}$ : the leverage length in $i$ th floor

$\dot{X}_{i}:$ the relative velocity in $i$ th floor

$X_{i}:$ the absolute displacement in $i$ th floor

$\dot{X}_{0}$ : the absolute velocity at rigid base

$X_{0}$ : the absolute displacement at rigid base

$M_{i}=\left(m_{c}\right)_{i}+\left(m_{s}\right)_{i}+(m l 1)_{i}$

$m_{c}$ : column mass $m_{s}$ : deck mass

$\alpha_{i}$ : the arm ration in $i$ th floor

$\left(I_{\alpha}\right)_{i}=\frac{\left(\alpha_{i}{ }^{2}-\alpha_{i}+1\right) m l_{i}{ }^{2}}{3\left(\alpha_{i}+1\right)^{2}}:$ the moment inertia in $i$ th floor

$m l 1, m l 2, m l 3$ : the leverage mass

From equation (2), the total potential energy includes collection from floor deck, damper and deformation of leverage.

$$
\begin{aligned}
V=\sum_{i=1}^{N} & \frac{1}{2} K_{i}\left(X_{i}-X_{i-1}\right)^{2}+\sum_{i=1}^{N} \frac{1}{2}\left(k_{d}\right)_{i}\left[\alpha_{i}\left(X_{i}-X_{i-1}\right)-\frac{2 \alpha_{i} \theta_{i} l_{i}}{\left(1+\alpha_{i}\right)}\right]^{2} \\
& +\sum_{i=1}^{N} \frac{1}{2} k_{i}\left[\frac{l_{i} \theta_{i}}{\left(1+\alpha_{i}\right)}\right]^{2}+\sum_{i=1}^{N} \frac{1}{2} \frac{k_{i}}{\alpha_{i}^{3}}\left[\frac{\alpha_{i} l_{i} \theta_{i}}{\left(1+\alpha_{i}\right)}\right]^{2}
\end{aligned}
$$



$K_{i}$ : the stiffness of $i$ th floor
$k_{d}$ : the stiffness of linear fluid damper
$k_{i}$ : the stiffness of leverage arm in $i$ th floor

The energy dissipation, $\triangle w$ in equation (3), is the sum of damping from structural members and dampers. If leverage device is rigid enough to omit the deformation and rotational velocity, a multiplier, $\alpha{ }^{2} C_{a}$, means the folds to improve the performance of damper device.

$$
\begin{gathered}
\left.\Delta w=-\sum_{i=1}^{N} C_{i}\left(\dot{X}_{i}-\dot{X}_{i-1}\right)\left(X_{i}-X_{i-1}\right)\right] \\
-\sum_{i=1}^{N}\left(C_{a}\right)_{i}\left[\alpha_{i}\left(\dot{X}_{i}-\dot{X}_{i-1}\right)-\frac{2 \alpha_{i} \dot{\theta}_{i} l_{i}}{\left(1+\alpha_{i}\right)}\right] \cdot\left[\alpha_{i}\left(X_{i}-X_{i-1}\right)-\frac{2 \alpha_{i} \theta_{i} l_{i}}{\left(1+\alpha_{i}\right)}\right] \\
C_{i}: \text { the damping in } i \text { th floor } \\
C_{a}: \text { the damping of linear fluid damper }
\end{gathered}
$$

By Lagrange equation, the motion equation of building structure with EDS could be derived in equation (4). The detailed content of each matrix can be consulted in the reference [3].

$$
[M]\{\ddot{U}\}+[C]\{\dot{U}\}+[K]\{U\}=-[M] \ddot{X}_{0}
$$

\section{Numerical simulation}

A 10-story numerical model with 5 and 4 bays in both directions is established to explore the seismic response by SAP2000, as shown in Figure 4. In the model, the connection joint at girder and leverage arm is hinge type with displacement constraints in $\mathrm{X}$ and $\mathrm{Y}$ directions. Other hinge type connectors, free rotating in $\mathrm{Y}$ axis, are located at anchorages of damper's both ends connecting to rigid leverage and braced seat [4].

In numerical case study, Chi-Chi Earthquake (1999, Taiwan) is chosen as the input ground motion with $0.33 \mathrm{~g}$ PGA to verify the efficiency of EDS. One of the numerical cases, whose EDS's arm ratio $(\alpha)$ is adjusted to 3 by 24 damper (damping coefficient $\mathrm{C}=350 \mathrm{KN} / \mathrm{m} / \mathrm{s}$ ), is compared with empty structure. The damping ratios for with- or without- EDS are $30 \%$ and $5 \%$ respectively. From numerical results, in figure 5, the maximum story drift ratio decreases from $8.62 / 1000$ to $4.97 / 1000$ and maximum share force from $24,428 \mathrm{KN}$ to $14,633 \mathrm{KN}$. 

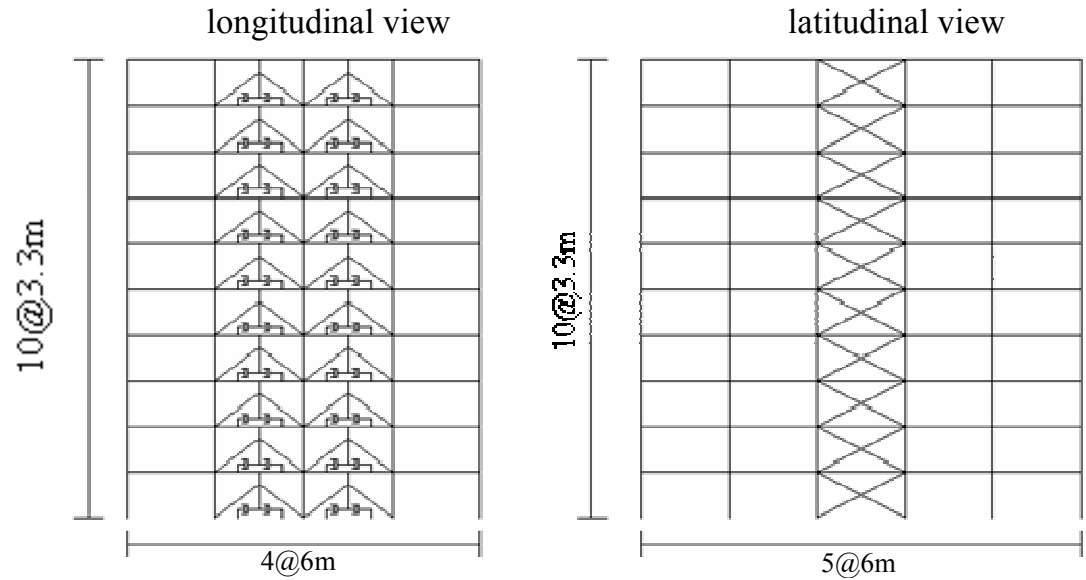

Figure 4: $\quad$ 10-story model with longitudinal and latitudinal views.
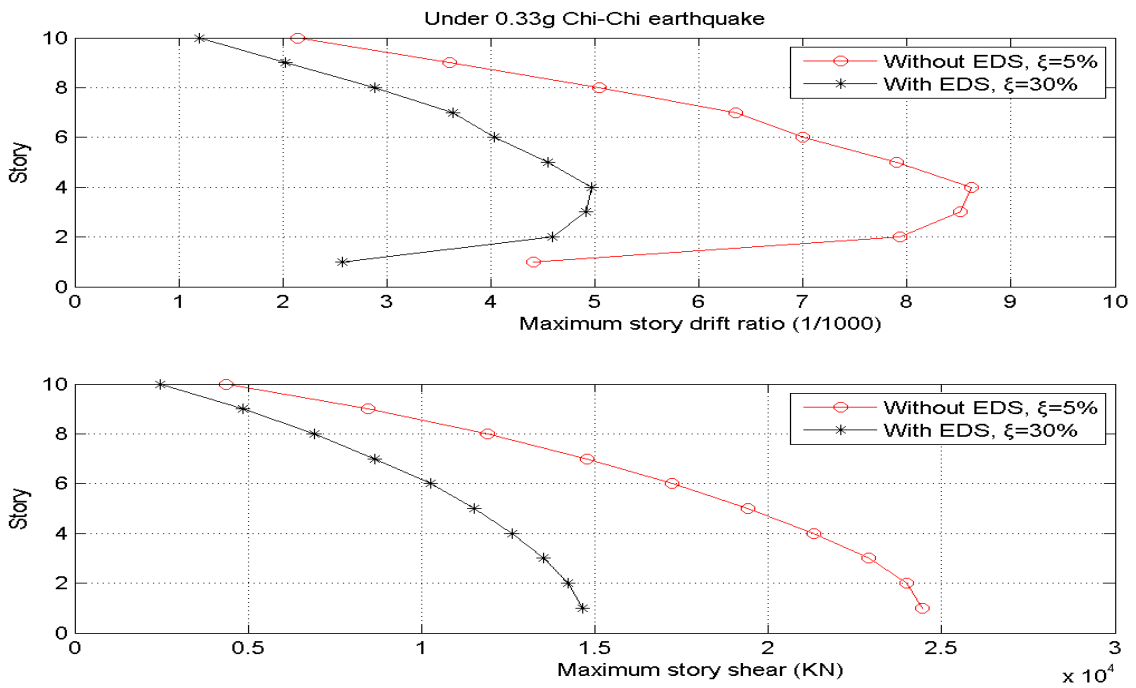

Figure 5: Story drift ratio and story shear of 10-story building model with/without EDS under 0.33g Chi-Chi earthquake.

\section{Shaking table experiments}

To verify the effectiveness in reductions of relative displacement and shear of the damping system, a three-story building model (full-scale steel structure) with EDS is set up for bi-axial shaking table tests. The building model is $4.5 \mathrm{~m}$ in length (x-direction), $3 \mathrm{~m}$ in width (y-direction), and $9 \mathrm{~m}$ in height. The mass of the building model including two concrete blocks bolted in each story is 38-ton. The 
$1^{\text {st }}$ and $2^{\text {nd }}$ natural frequencies of building model are $1.17 \mathrm{~Hz}$ (x-direction) and $3.67 \mathrm{~Hz}$ (y-direction). Design and installation of EDS is shown in figures 6-7[5].

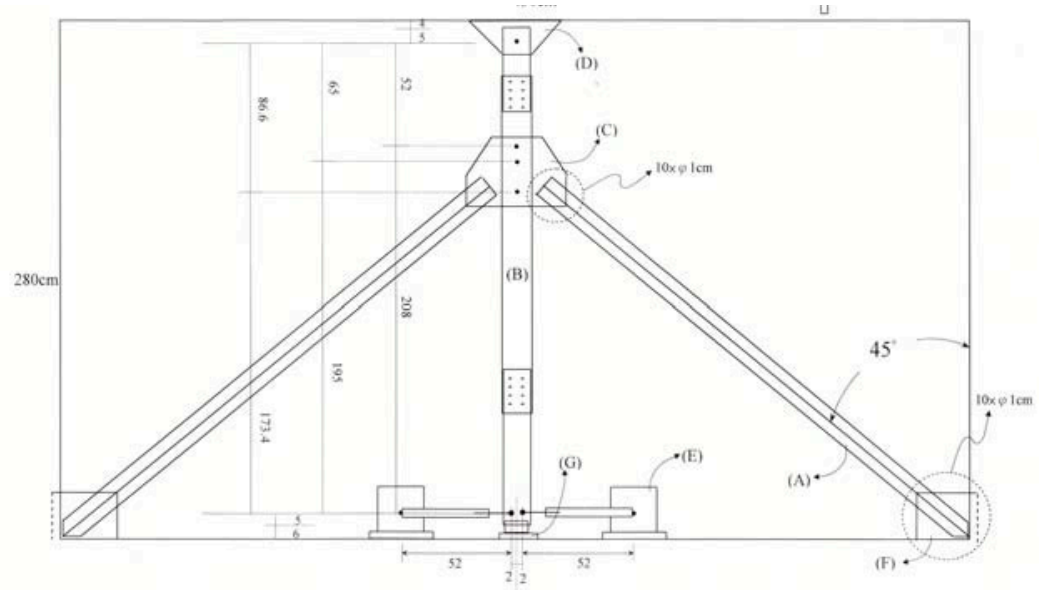

Figure 6: The sketch and dimensions of EDS. (Unit: $\mathrm{cm}$.)

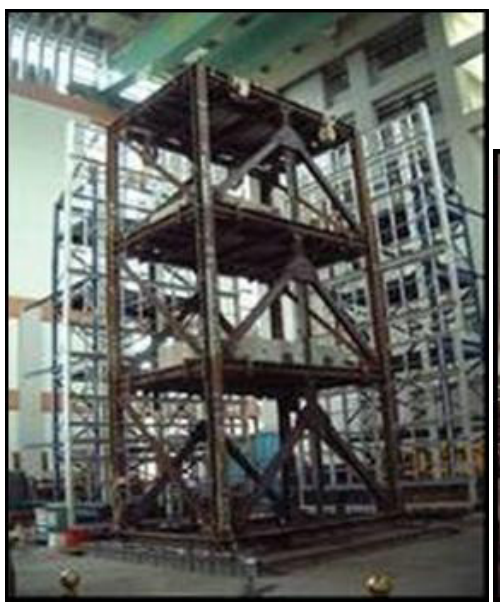

(a)

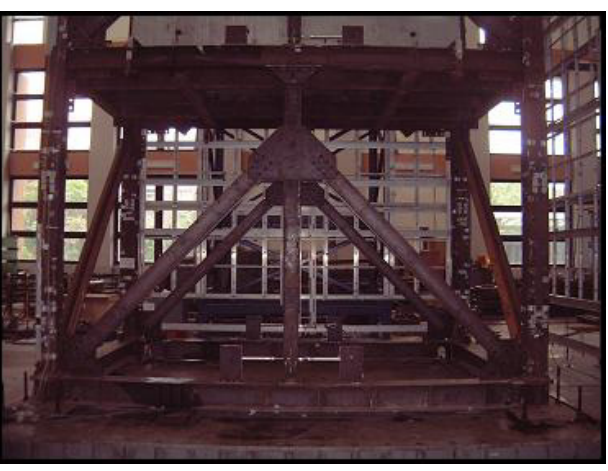

(b)

Figure 7: (a) Steel building model with EDS. (b) Installation of EDS.

During shaking table experiments, the applied damper has the dimensions of $66 \mathrm{~cm}$ in length and $20 \mathrm{~cm}$ in stroke. As compared with frequently used damper, the adopted one is relatively small. With the arm ratios of 2, 3, 4, the outcomes tell the limited number of damper in EDS will significantly enhance the damper ratio of 38-ton steel frame from $3 \%$ to $15 \% \sim 35 \%$. And the reduction ratio of relative displacement to first floor ranges from $62 \% \sim 72 \%$, depicted in figure 8 . In figure 9 , closeness between the test results and the numerical simulations is presented. 
148 Earthquake Resistant Engineering Structures VI
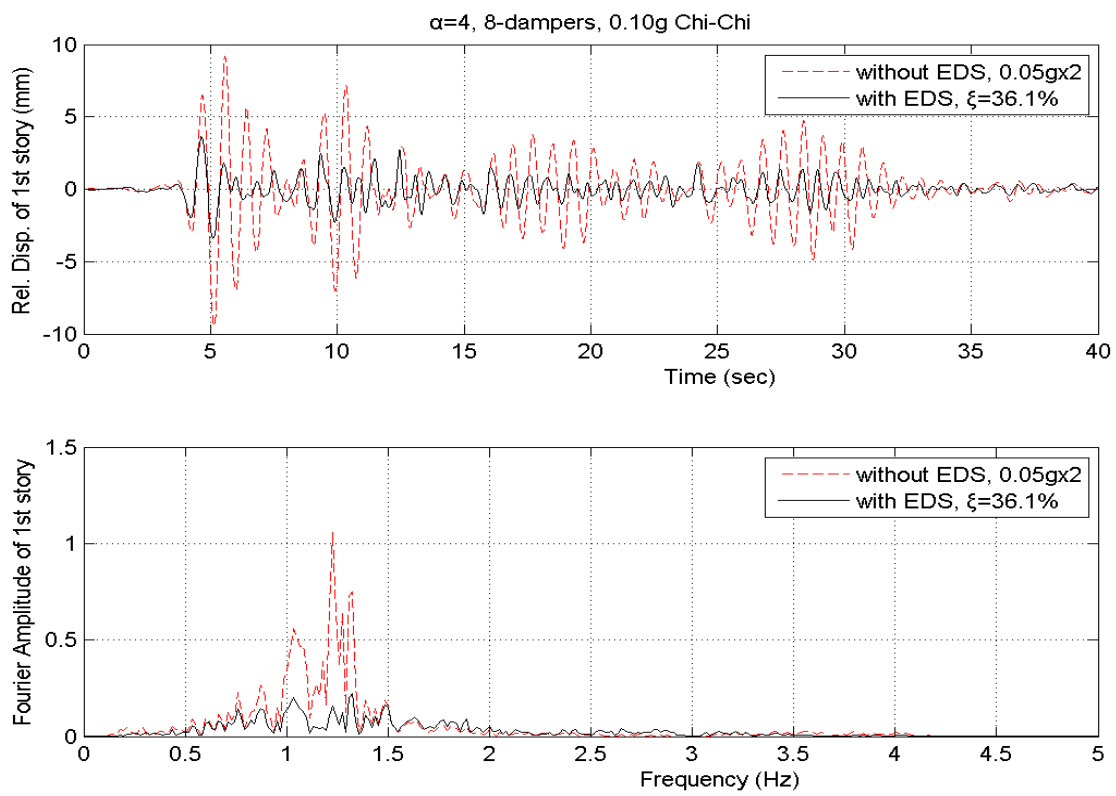

Figure 8: Responses of the building model with/without EDS under 0.1g ChiChi earthquake.
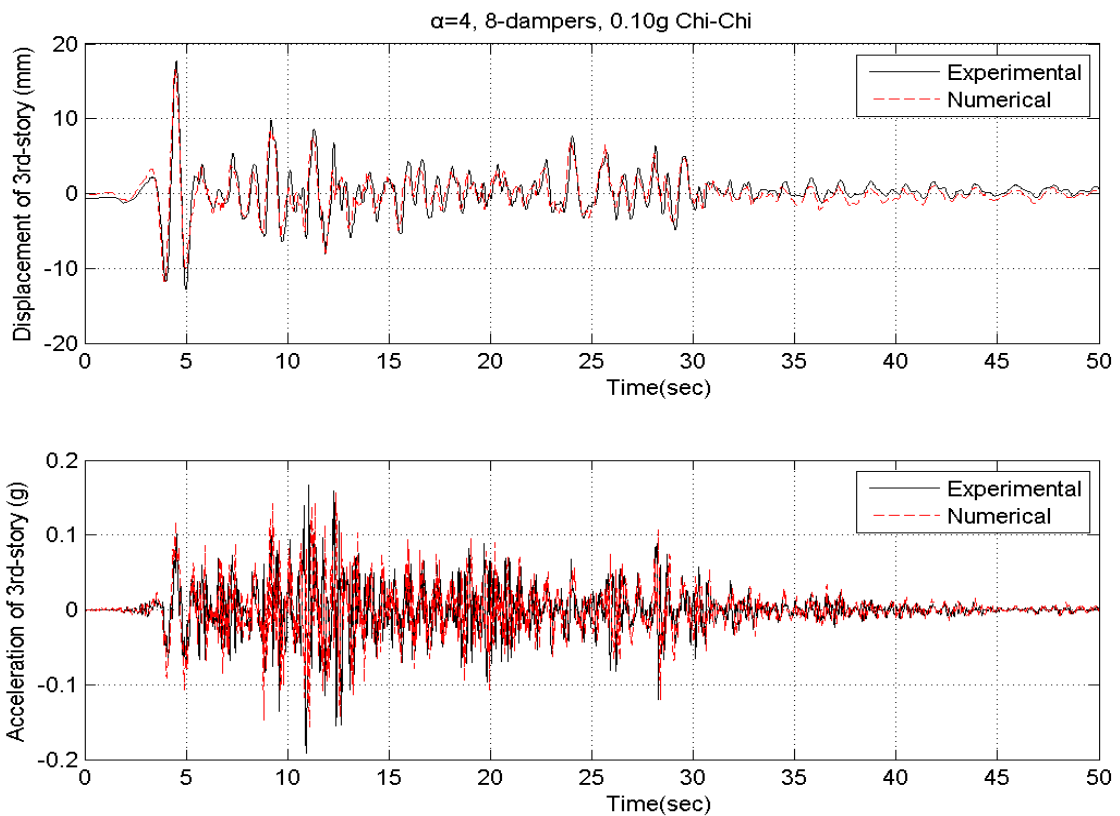

Figure 9: Numerical simulations and experimental results of the building model. 


\section{Conclusions}

A new damping device system is proposed. Based on the results of the theoretical analysis, it is found that not only the maximum relative displacement but also the maximum base shear can be reduced significantly if the device system has been used on the building. In addition, the results of building model shaking table tests tell us that the aseismic capabilities of the building models are largely increased due to the energy dissipation characteristics of the device system. Further more the linear approach used in numerical analysis of the building model with EDS and corresponding results, also demonstrate the simplicity in analysis. In conclusion, it is suggested that this device system be applied in the design of new buildings as in the retrofitting of existing buildings with inadequate aseismic strength.

\section{References}

[1] Shinozuka, M. et al, Passive and Active Fluid Dampers in Structural Applications, US, China, Japan, Workshop on Structural Control, pp.1-9, Shanghai, China, 1992.

[2] Tang, J.P., Ke, S.S. \& Ke, C.L., Aseismic Study of Heavily Damped Building Structure, Journal of the Chinese Institute of Civil and Hydraulic Engineering, 13(4), pp.793-804, 2001. (in Chinese)

[3] Ke, S.S., Aseismic Study of the Building With the Efficiency-enhanced Damping System, Ph.D. Thesis , C.E. Dept., National Central University, Taiwan, 2004. ( in Chinese)

[4] Tang, J.P., Ke, S.S. \& Wu, H.D., Seismic Retrofitting Study of the Building With the Efficiency-enhanced Damping System, Structural Engineering, Vol.19, No.3, pp.3-28, 2004. ( in Chinese)

[5] Tang, J.P., Ke, S.S. \& Lai, H.K., The Building Equipped with the EDS Subjected to 2D Horizontal Shaking Table Tests and Analyses, Structural Engineering, Vol.18, No.1, pp.3-36, 2003. (in Chinese) 